\section{CoSci ech}

p-ISSN: 2723-567X

e-ISSN: 2723-5661
Jurnal Computer Science and Information Technology (CoSciTech)

http://ejurnal.umri.ac.id/index.php/coscitech/index

\title{
Sistem Pendukung Keputusan Penilaian Kinerja Pegawai di Klinik Bunda Medical Center (BMC) dengan Menggunakan Metode Simple Additive Weighting (SAW)
}

\author{
Yulia Fatma ${ }^{1}$, Januar Al Amien ${ }^{2}$, Riski Hakiki ${ }^{3}$, Febby Apri Wenando ${ }^{4}$ \\ email: ${ }^{1}$ yuliafatma@umri.ac.id, ${ }^{2}$ januaralamien@umri.ac.id, ${ }^{3} 170401029 @$ student.umri.ac.id, ${ }^{4}$ febbyapri@umri.ac.id
}

${ }^{1234}$ Teknik Informatika, Fakultas Ilmu Komputer, Universitas Muhammadiyah Riau

Diterima: 08 Oktober 2021 | Direvisi: - | Disetujui: 20 Desember 2021

(C)2021 Program Studi Teknik Informatika Fakultas Ilmu Komputer,

Universitas Muhammadiyah Riau, Indonesia

\begin{abstract}
Abstrak
Penilaian kinerja merupakan suatu proses organisasi dalam menilai untuk kinerja pegawainya. Tujuan dilakukan penilaian kinerja untuk memberikan feedback kepada pegawai dalam upaya meningkatkan produktivitas organisasi, dan secara khusus dilakukan dalam kaitannya dengan berbagai kebijaksanaan terhadap pegawai diberikan bonus gaji dan mengevaluasi dari hasil kinerja pegawai. Masalah inilah yang membuat Klinik Bunda Medical Center (BMC) mencari solusi agar penilaian kinerja pegawai dapat dilakukan secara adil, realistis valid dan relevan. Sistem Pendukung Keputusan (SPK) Penilaian Kinerja pegawai adalah sebuah sistem yang dapat membantu HRD dalam menentukan keputusan pegawai dengan kinerja yang baik untuk mendapatkan bonus gaji. Kriteria yang digunakan untuk mengukur kinerja pegawai ada 5 kriteria, yaitu Kedisiplinan, Team Work,Kejujuran,Tanggung Jawab,Tepat Waktu. Sistem ini menggunakan metode Simple Additive Weighting (SAW) yang merupakan metode penilaian yang diukur dari nilai suatu bobot kriteria yang dikelompokan dalam bobot nilai kriteria yang bersifat benefit. Dengan menggunakan sistem pendukung keputusan ini dapat membantu HRD untuk dalam melakukan penilaian kinerja pegawai di Klinik Bunda Medical Center (BMC). Hasil akhir penghitungan dari SAW, menunjukkan bahwa alternatif A5 atas nama Miftakhul Jannah, S.Kom, adalah pegawai terbaik dengan jumlah nilai tertinggi yaitu 1.
\end{abstract}

Kata kunci: Penilaian,Sistem Pendukung Keputusan, Kriteria, Simple Additive Weighting (SAW), Benefit, Alternatif

\section{Decision Support System for Employee Performance Assessment at Bunda Medical Center (BMC) Clinic by Using the Simple Additive Weighting (SAW) Method}

\begin{abstract}
Performance appraisal is an organizational process in assessing the performance of its employees. The purpose of performance appraisal is to provide feedback to employees in an effort to increase organizational productivity, and specifically in relation to various policies for employees to be given salary bonuses and evaluate the results of employee performance. This problem makes Bunda Medical Center (BMC) Clinic look for solutions so that employee performance appraisals can be carried out fairly, realistically, validly and relevantly. Decision Support System (SPK) Employee Performance Assessment is a system that can assist HRD in determining the decisions of employees with good performance to get salary bonuses. The criteria used to measure employee performance are 5 criteria, namely Discipline, Team Work, Honesty, Responsibility, Punctuality. This system uses the Simple Additive Weighting (SAW) method, which is an assessment method that is measured by the value of a criterion weight which is grouped in the weight of the criterion value that is benefit. By using this decision support system, HRD can assist in evaluating employee performance at the Bunda Medical Center (BMC) Clinic. The final result of the calculation from SAW, shows that alternative A5 on behalf of Miftakhul Jannah, S.Kom, is the best employee with the highest total score of 1.
\end{abstract}

Keywords: Assessment, Decision Support System, Criteria, Simple Additive Weighting (SAW), Benefit, Alternative 


\section{Pendahuluan}

Berkembangnya ilmu pengetahuan dan teknologi di era globalisasi saat ini membuat masyarakat semakin kritis tentang dunia kesehatan dan menuntut adanya kualitas pelayanan yang baik [1]. Klinik dinyatakan berhasil apabila sikap dan layanan sumber daya manusia merupakan elemen yang berpengaruh signifikan terhadap pelayanan yang dihasilkan dan dipersepsikan pasien. Klinik mengharapkan memiliki pegawai yang menampilkan kinerja yang professional [2].

Pegawai yang berkualitas akan meningkatkan mutu pelayanan masyarakat pada sebuah instansi. Upaya yang dilakukan untuk memacu pegawai bekerja lebih baik dan berprestasi[3], sebuah instansi dapat memberikan penghargaan kepada para pegawai yang dianggap berkompeten dalam melakukan perkerjaan dalam sebuah instansi. Untuk mempermudah penilaian kinerja pegawai [4].

Penilaian kinerja merupakan suatu proses penilaian yang sistematis yang terarah dan terpadu dalam menilai keseluruhan unsur-unsur yang dimiliki oleh karyawan sebagai pekerja yang produktif [5]. Penilaian tersebut memiliki arti penting bagi kalangan karyawan dan organisasi, dimana metode penilaian yang diterapkan dan bagaimana hasil penilaian dikomunikasikan akan menyebabkan hal positif maupun negatif terhadap moral kerja karyawan [6].

Dalam penelitian ini, terdapat kendala pada Klinik BMC yaitu belum adanya penilaian kinerja pegawai. karena ruang lingkup kerjanya masih kecil dan masih melakukan secara persuasif. sistem penilaian di Klinik BMC ini menggunakan sistem kekeluargaan, maka dari itu penilaian kinerja pegawai untuk saat ini belum diterapkan. karena Klinik BMC ini belum adanya sistem yang mendukung untuk keputusan penilaian kinerja. Oleh karena itu klinik harus memiliki kebijakan dalam penilaian kinerja digunakan untuk mengevaluasi hasil kerja seluruh pegawai dengan menggunakan kriteria Kedisiplinan, Team Work, Kejujuran, Tanggung Jawab dan Tepat waktu.

Sistem Pendukung Keputusan merupakan suatu sistem berbasis komputer yang membantu manager dalam menyelesaikan masalah baik terstruktur maupun tidak terstruktur dengan menggunakan data dan metode [7]. Keputusan yang baik dihasilkan dari proses yang objektif dan hal ini mampu diselesaikan dengan penggunakan SPK Penerapan metode metode [8]. dalam penghasilan keputusan perlu di lakukan agar hasil yang diberikan dapat dipertanggung jawabkan dengan baik [9].

Pada penelitian ini menggunakan metode Simple Additive Weighting (SAW). Metode ini sangat mudah dan sederhana dalam menghasilkan keputusan. Konsep dasar metode Simple Additive Weighting(SAW) adalah mencari penjumlahan terbobot dari rating kinerja pada setiap alternatif pada semua atribut [10]. Metode SAW membutuhkan proses normalisasi matriks keputusan (X) ke suatu skala yang dapat diperbandingkan dengan semua rating alternatif yang ada. Pada metode SAW (Simple Additive Weighting) sebagai pembobotan kriteria sekaligus perangkingan [11]. Metode SAW bisa digunakan untuk pendukung pengambilan suatu keputusan dengan menghasilkan nilai terbesar sebagai keputusan yang terbaik.

\section{Metode Penelitian}

Konsep dasar metode Simple Additive Weighting(SAW) adalah mencari penjumlahan terbobot dari rating kinerja pada setiap alternatif pada semua atribut. Adapun langkah-langkah yang dapat dilakukan dalam SAW yaitu :

1. Menentukan kriteria-kriteria yang akan dijadikan acuan dalam pengambilan keputusan, yaitu Ci.

2. Menentukan rating kecocokan setiap alternative pada setiap kriteria.

3. Membuat matriks keputusan berdasarkan kriteria, kemudian melakukan normalisasi matriks berdasarkan persamaan yang disesuaikan dengan jenis atribut benefit ataupun cost sehingga diperoleh matriks ternormalisasi.

4. Hasil akhir diperoleh dari proses perankingan yaitu penjumlahan dari perkalian matriks ternormalisasi dengan bobot sehingga diperoleh nilai terbesar yang dipilih sebagai alternative terbaik sebagai solusi

Tahap ini melakukan normalisasi matriks berdasarkan persamaan yang disesuaikan dengan jenis atribut (atribut keuntungan atau atribut biaya) sehingga diperoleh matriks ternormalisasi R.

Rumus algoritma SAW dapat ditunjukkan oleh persamaan yaitu :

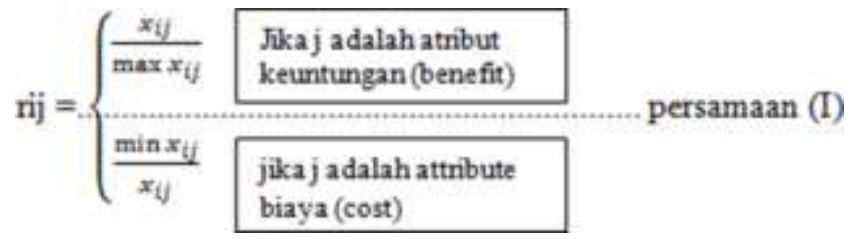

Gambar 1. Rumus Algoritma SAW

Keterengan :

Rij : Nilai rating kinerja ternomalisasi

$\mathrm{Xij} \quad$ : Nilai atribut yang dimiliki setiap kriteria

MaXi Xij : Nilai terbesar dari setiap kriteria

Mini Xij : Nilai terkecil dari setiap kriteria

Benefit : Jika nilai terbesar adalah terbaik

Cost : Jila nilai terkecil adalah terbaik

Dimana Rij adalah rating kinerja ternormalisasi dari alternatif Ai pada atribut $\mathrm{Cj} ; \mathrm{i}=1,2, \ldots, \mathrm{m}$ dan $\mathrm{j}=1,2, \ldots, \mathrm{n}$. Nilai preferensi (Vi) diberikan dengan rumus persamaan (2): 


$$
\mathrm{Vi}=\sum_{j=1}^{n} \mathrm{w}_{j} r_{i j}
$$

Gambar 2. Rumus Algoritma SAW

Keterangan :

Viz = Nilai akhir dari alternatif

wj = Bobot yang telah ditentukan

rij= Normalisasi matriks

Nilai Vi yang lebih besar mengindikasikan bahwa alternatif Ai lebih terpilih.

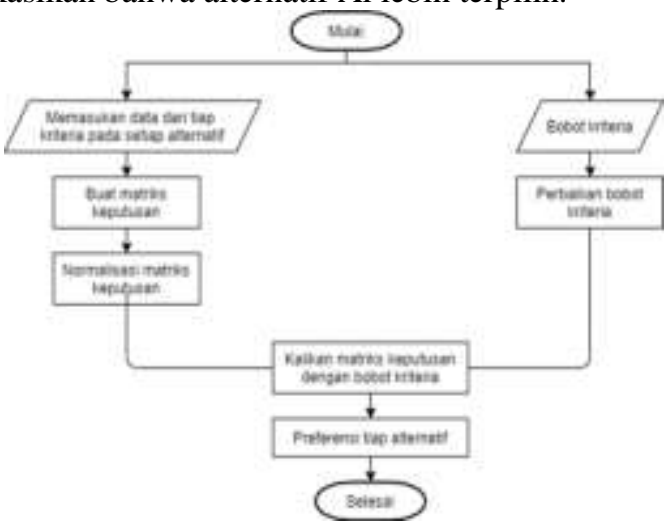

\subsection{Metode Waterfall}

Gambar 3. Diagram Alur Metode SAW

Kerangka Penelitian merupakan tahapan yang dilakukan oleh penulis untuk menyusun sebuah penelitian yang memiliki alur kerja yang jelas dan dapat menyelesaikan permasalahan yang akan dibahas pada tahapan pengembangan sistem. Berikut merupakan alur kerja penelitian :

\subsection{Metode Pengumpulan Data}

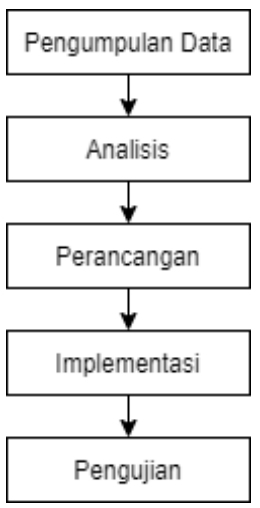

Gambar 4. Metode Waterfall

Adapun teknik Pengumpulan Data yang digunakan adalah sebagai berikut :

1. Studi Pustaka

Pada tahap studi literatur ini dapat mengambil referensi-referensi dari berbagai sumber penelitian terdahulu dan media internet. Sebagai pedoman untuk merancang sistem yang akan diusulkan untuk Klinik Bunda Medical Center (BMC)

2. Wawancara

Pada tahap wawancara yang dilakukan adalah proses tanya jawab dalam penelitian secara lisan dengan Bapak Armaini.SH selaku Kepala Bagian Klinik untuk mendapatkan informasi yang berkaitan dengan permasalahan dalam penelitian. Wawancara yang dilakukan terhadap informasi yang telah ditentukan untuk mendapatkan informasi yang lebih jelas dan mendalam dalam berbagai hal yang berhubungan dengan penelitian.

\subsection{Analisis Kebutuhan}

\section{Kebutuhan Fungsional}

Merupakan segala bentuk kebutuhan fungsional website yang dijabarkan satu persatu guna memudahkandalam tahapan perancangan, pengumpulan data serta tahapan implementasi sistem yang sesuai dengan kebutuhan sistem.

2. Kebutuhan Perangkas Keras dan Lunak 
Tabel 1. Spesifikasi Perangkat Keras

\begin{tabular}{|c|l|l|}
\hline No & \multicolumn{1}{|c|}{ Perangkat Keras } & \multicolumn{1}{|c|}{ Spesifikasi } \\
\hline 1 & Processor & Intel 2Core N3350, up to $2.4 \mathrm{GHz}$ \\
\hline 2 & Memory & RAM 4 GB \\
\hline 3 & Harddisk & HDD 500 GB \\
\hline
\end{tabular}

Tabel 2. Spesifikasi Perangkat Lunak

\begin{tabular}{|c|l|l|}
\hline No & \multicolumn{1}{|c|}{ Perangkat Keras } & \multicolumn{1}{c|}{ Spesifikasi } \\
\hline 1 & Sistem Operasi & Windows 10 \\
\hline 2 & Aplikasi & -Xampp / php \\
& & -Microsoft word \\
& & -Sublime Text 3.20 \\
& & -Google Chrome \\
\hline
\end{tabular}

\section{Hasil dan Pembahasan}

Pada analisa perancangan dijelaskan sebagai bahan perbandingan dengan sistem yang akan dirancang dan akan menjelaskan proses mengenai pengambilan keputusan tentang penilaian kinerja pegawai diklinik Bunda Medical Center(BMC).

Tabel 3. Tabel Kriteria

\begin{tabular}{|c|l|l|}
\hline No & \multicolumn{1}{|c|}{ Kode Kriteria } & \multicolumn{1}{|c|}{ Nama Kriteria } \\
\hline 1 & K1 & Kedisiplinan \\
\hline 2 & K2 & Team work \\
\hline 3 & K3 & Kejujuran \\
\hline 4 & K4 & Tanggung jawab \\
\hline 5 & K5 & Tepat waktu \\
\hline
\end{tabular}

Tabel 4. Matriks Keputusan

\begin{tabular}{lllll|}
81 & 80 & 81 & 83 & 81 \\
81 & 80 & 81 & 85 & 82 \\
81 & 80 & 81 & 81 & 83 \\
81 & 81 & 81 & 81 & 83 \\
85 & 85 & 85 & 85 & 85 \\
80 & 80 & 81 & 82 & 80 \\
81 & 81 & 81 & 83 & 81 \\
81 & 80 & 81 & 81 & 82 \\
82 & 82 & 82 & 80 & 81 \\
81 & 82 & 81 & 80 & 80 \\
80 & 81 & 81 & 80 & 81 \\
81 & 82 & 81 & 81 & 81 \\
82 & 82 & 81 & 82 & 82
\end{tabular}

Tabel 5. Penentuan Nilai Bobot Kriteria

\begin{tabular}{|c|l|c|}
\hline Kriteria & \multicolumn{1}{|c|}{ Keterangan } & Bobot \\
\hline K1 & Kedisiplinan & $25 \%$ \\
\hline K2 & Team work & $15 \%$ \\
\hline K3 & Kejujuran & $25 \%$ \\
\hline K4 & Tanggung jawab & $25 \%$ \\
\hline K5 & Tepat waktu & $10 \%$ \\
\hline
\end{tabular}

Dari rumus perhitungan diatas, maka dihasilkan matriks ternormalisasi Rij seperti dibawah ini : 


\begin{tabular}{|c|c|c|c|c|}
\hline 0.9529 & 0.9412 & 0.9529 & 0.9765 & 0.9529 \\
0.9529 & 0.9412 & 0.9529 & 1 & 0.9647 \\
\hline 0.9529 & 0.9412 & 0.9529 & 0.9529 & 0.9765 \\
0.9529 & 0.9529 & 0.9529 & 0.9529 & 0.9765 \\
\hline 1 & 1 & 1 & 1 & 1 \\
0.9412 & 0.9412 & 0.9529 & 0.9647 & 0.9412 \\
0.9529 & 0.9529 & 0.9529 & 0.9765 & 0.9529 \\
\hline 0.9529 & 0.9412 & 0.9529 & 0.9529 & 0.96471 \\
0.9647 & 0.9647 & 0.9647 & 0.9412 & 0.9529 \\
\hline 0.9529 & 0.9647 & 0.9529 & 0.9412 & 0.9412 \\
\hline 0.9412 & 0.9529 & 0.9529 & 0.9412 & 0.9529 \\
\hline 0.9529 & 0.9647 & 0.9529 & 0.9529 & 0.9529 \\
\hline 0.9647 & 0.9647 & 0.9529 & 0.9647 & 0.9647 \\
\hline
\end{tabular}

Tabel 6. Matriks Ternormalisasi

3.1. Proses Perangkingan

Rumus :

$V i=\sum_{j=1}^{n}$ Wjrij

Keterangan :

$\mathrm{Vi}=$ Nilai akhir dari alternatif

$\mathrm{Wj}=$ Bobt yang telah ditentukan

Rij = Normalisasi matriks

Perangkingan pegawai dengan nilai bobot (w) dengan kriteria :

$\left[\begin{array}{lllll}25 & 15 & 25 & 25 & 10\end{array}\right]$

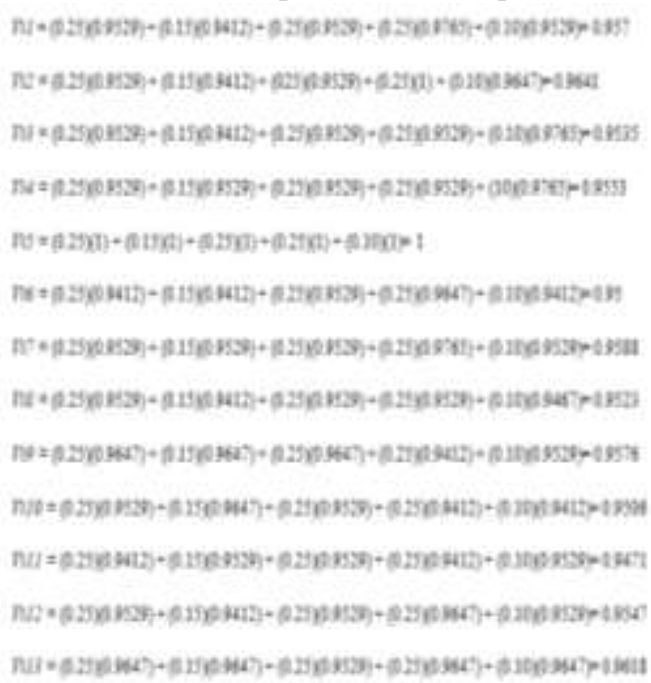

Tabel 7. Hasil Penilaian Sebelum Perankingan 


\begin{tabular}{|c|c|c|}
\hline No. & Nama & Nilai \\
\hline 1. & Yuli Asnita, Amd,Keb & 0.957 \\
\hline 2 & Oca Jumia Safitri, Amd Keb & 0.9641 \\
\hline 3. & Exri Novita Sari_Amd Ke甲 & 09535 \\
\hline 4. & Utin Atika Sari & 0.9553 \\
\hline 5. & Miftakhul Jannah_Skom & 1 \\
\hline 6. & Erizal & 0.95 \\
\hline 7. & Nada Salsabila & 0.9588 \\
\hline 8. & Taty Komala Sari, Skep & 0.9523 \\
\hline 9. & Utamimma & 0.9576 \\
\hline 10. & Lilik, And Ak & 0.9506 \\
\hline 11. & Viouna Cahyani & 09471 \\
\hline 12 & Kenny Carolina, Amd.Ak & 0.9547 \\
\hline 13 & Nur Indah Melati, And Apt & 0.9618 \\
\hline
\end{tabular}

Dari hasil perhitungan dengan metode Simple Additive Weighting (SAW) diatas, mka akan didapat penilaian pegawai dengan nilai yang paling tinggi. Adapun hasilnya adalah sebagai berikut :

Tabel 8. Hasil penilaian sesudah perangkingan

\begin{tabular}{|c|c|c|}
\hline $\mathrm{Y}_{0 .}$ & Nama & Nilai \\
\hline 1 & Miftakhul Jannah,S kom & 1 \\
\hline 2. & Oca Junia Safitri, Amd Keb & 0.9641 \\
\hline 3. & Nur Indah Nelati, Amd Apt & 0.9618 \\
\hline 4. & Nada Salsabila & 0.9588 \\
\hline 5. & Utamimima & 0.9576 \\
\hline 6. & Yuli Asnitz, And Keb & 0.9570 \\
\hline 7. & Utin Atika Sani & 0.9553 \\
\hline 8. & Kenny Carolina, Amd Ak & 0.9547 \\
\hline 9. & Etri Novita SariAmd,Kep & 0.9535 \\
\hline 10. & Taty Romala Sari, S Kep & 0.9523 \\
\hline 11. & Lilk, And Ak & 0.9506 \\
\hline 12 & Enzal & 0.9500 \\
\hline 13 & Viona Cahyani & 0.9471 \\
\hline
\end{tabular}

\subsection{Implementasi Sistem}

Tahap implementasi merupakan tahap penulisan kode program sesuai dengan bahasa pemrograman disertai desain sistem yang telah dirancang sebelumnya. Pada tahapan ini sistem siap dibangun sesuai dengan kebutuhan user agar sistem dapat dioperasikan dengan baik. Adapun hasil implementasi dari sistem pendukung keputusan penilaian kinerja pegawai di klinik Bunda Medical Center (BMC) adalah sebagai berikut :

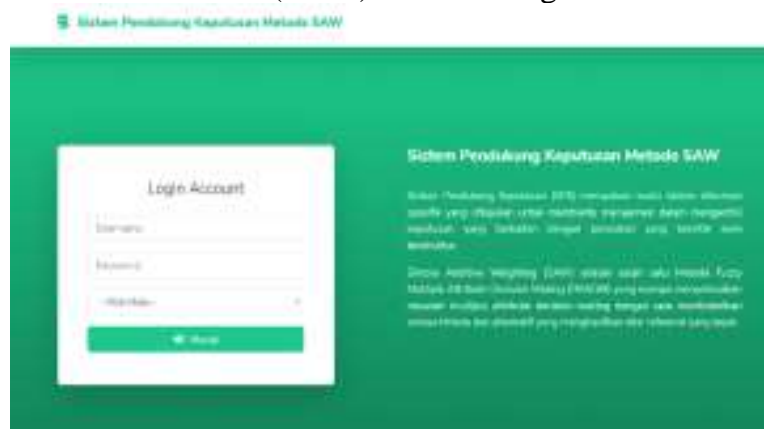

Gambar 5. Tampilan halaman login

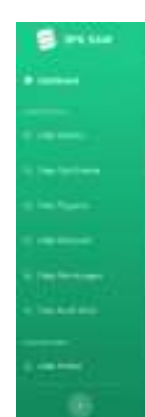

Gambar 6. Halaman Dashboard 


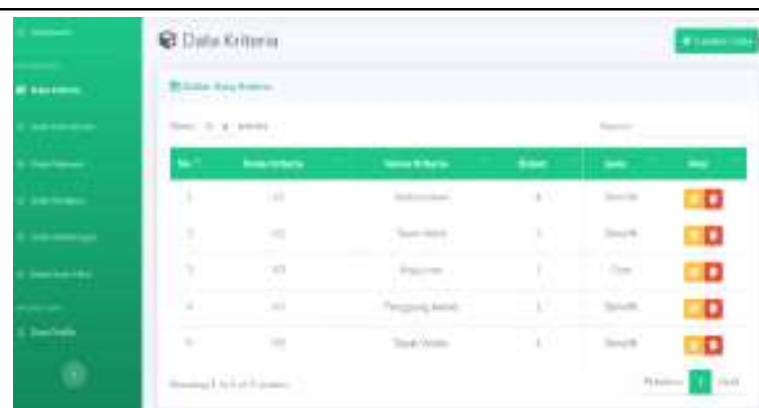

Gambar 7. Halaman Data Kriteria
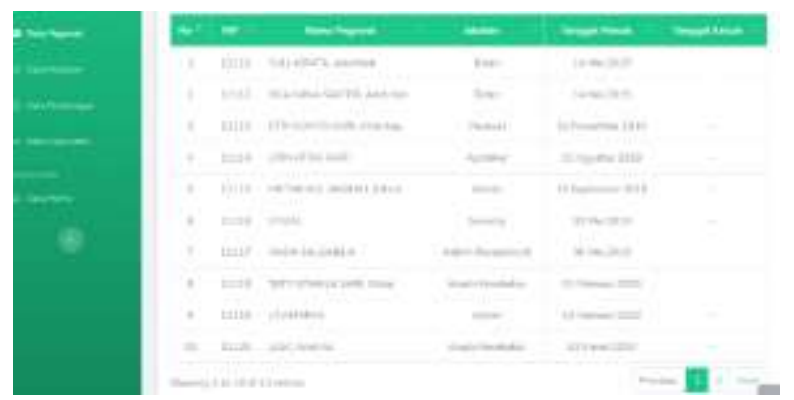

Gambar 9. Halaman Data Pegawai

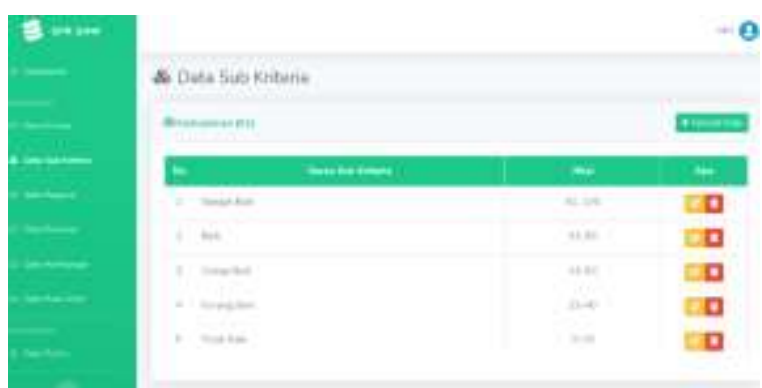

Gambar 8. Halaman Data SubKriteria
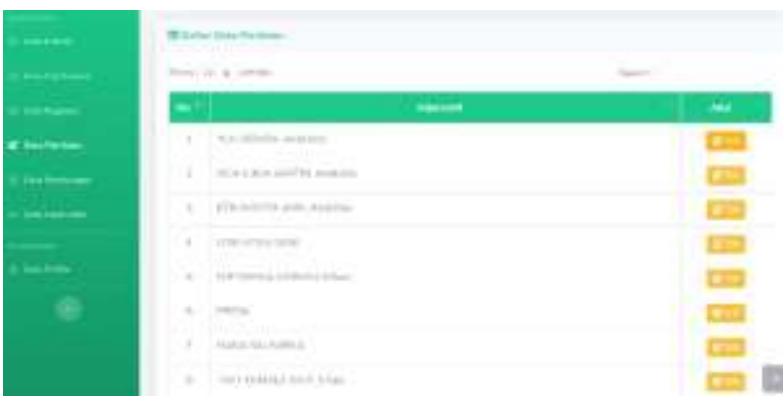

Gambar 10. Halaman Data Penilaian
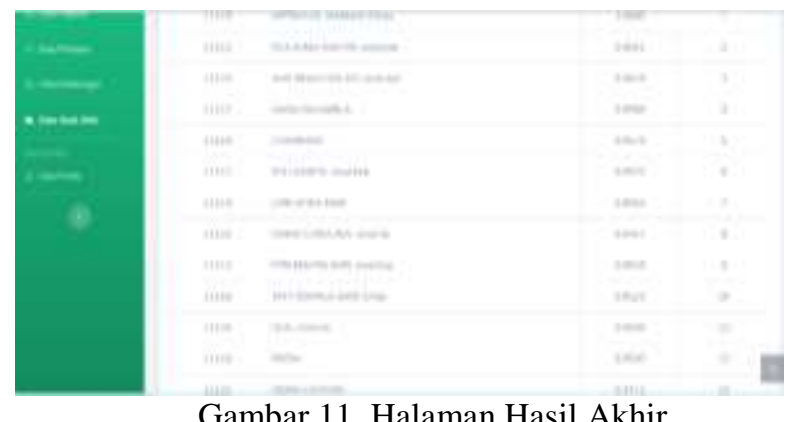

\subsection{Pengujian Sistem}

Setelah melakukan tahapan implementasi sistem dan tahapan terakhir dari semua tahapan ialah melakukan pengujian sistem. Tahapan pengujian ini dilakukan bertujuan untuk menguji semua elemen-elemen yang telah dibuar dan di implementasikan apakah sesuai dengan yang diharapkan. Dalam tahapan pengujian sistem tersebut digunakan metode Blackbox

\begin{tabular}{|c|c|c|c|c|}
\hline No & Fungsi yg diuji coba & Cara pengujian & Hasil yang diarapkan & Hasil pengujian \\
\hline 1 & Login admin & $\begin{array}{l}\text { Memasukkan username danpassword serta memilih } \\
\text { role admin }\end{array}$ & Masuk kedalam sistem & Sukses \\
\hline 2 & Login HRD & $\begin{array}{l}\text { Memasukkan username dan password serta memilih } \\
\text { role HRD }\end{array}$ & Masuk ke dalam sistem & Sukses \\
\hline 3 & Login manager & $\begin{array}{l}\text { Memasukkan username dan password serta memilih } \\
\text { role manager }\end{array}$ & Masuk ke dalam sistem & Sukses \\
\hline 4 & Menu Kriteria & $\begin{array}{l}\text { Admin dan HRD Memasukkan data kriteria baru dan } \\
\text { menghapus data kriteria }\end{array}$ & $\begin{array}{l}\text { Data dapat disimpan lalu ditampilkan oleh } \\
\text { sistem dan data dapat dihapus }\end{array}$ & Sukses \\
\hline 5 & Menu Alternatif & $\begin{array}{l}\text { Admin Memasukkan data alternatif baru dan } \\
\text { menghapus data alternatif }\end{array}$ & $\begin{array}{l}\text { Data dapat disimpan lalu ditampilkan oleh } \\
\text { sistem dan data dapat dihapus }\end{array}$ & Sukses \\
\hline 6 & Menu Penilaian & $\begin{array}{l}\text { HRD Memasukkan data penilaian baru, menghapus } \\
\text { data berdasarkan id, dan menghapus semua data } \\
\text { penilaian }\end{array}$ & $\begin{array}{l}\text { Data dapat disimpan dan ditampilkan } \\
\text { sesuai dengan yang dimasukkan. Dapat } \\
\text { menghapus berdasarkan id dan semua data } \\
\text { penilaian }\end{array}$ & Sukses \\
\hline 7 & Hasil Perhitungan & $\begin{array}{l}\text { Mencocokkan hasil perhitungan manual dengan } \\
\text { perhitungan sistem }\end{array}$ & Perhitungan yang dihasilkan sesuai & Sukses \\
\hline 8 & Data Hasil Akhir & Manajer Menekan tombol Cetak PDF & $\begin{array}{l}\text { Data hasil perhitungan dapat di ekspor } \\
\text { dalam bentuk PDF }\end{array}$ & Sukses \\
\hline 9 & Logout & Semua user Menekan menu Keluar & Kembali ke menu login & Sukses \\
\hline
\end{tabular}




\section{KESIMPULAN}

Berdasarkan penelitian yang telah dilakukan maka dapat ditarik beberapa kesimpulan sebagai berikut :

1. Sistem Pendukung Keputusan berhasil dibangun menggunakan Metode Simple Additive Weighting (SAW) untuk membantu pihak instansi dalam melakukan penilaian kinerja pegawai sesuai kriteria yang telah ditetetapkan.

2. Metode Simple Additive Weighting $(S A W)$ dapat diterapkan pada sistem yang digunakan untuk memberikan penilaian kinerja pegawai pada Klinik dan mendapatkan hasil perangkingan.

\section{DAftar Pustaka}

[1] U. Maghfur and M. H. Wahyudi, "Sistem Pendukung Keputusan Penilaian Kinerja Pegawai Pelayanan Administrasi Terpadu Kecamatan (Paten) Di Kecamatan Pucuk Menggunakan Metode Ahp Berbasis Web,” J. Tek., vol. 10, no. 1, p. 983, 2018, doi: 10.30736/teknika.v10i1.205.

[2] I. Agus, F. Marisa, and I. D. Wijaya, "Sistem Pendukung Keputusan Penerimaan Dan Penilaian Karyawan Warehouse Dengan Aplikasi Web," JOINTECS (Journal Inf. Technol. Comput. Sci., vol. 2, no. 1, 2017, doi: 10.31328/jointecs.v2i1.413.

[3] N. Sudarsono, N. Suciyono, and A. Kuswandi, "Sistem pendukung Keputusan ( SPK ) Pemberian Kredit di Adira Quantum Multifinance Cabang Tasikmalaya Metode Simple Additive Weighting ( SAW )," Konf. Nas. Sist. Inform., pp. 9-10, 2015.

[4] T. B. Sunardi and D. Kriestanto, "Perbandingan AHP dan SAW Untuk Pemilihan Pegawai Terbaik (Studi Kasus: STMIK AKAKOM Yogyakarta),” Semin. Ris. Teknol. Inf., p. 9, 2016.

[5] C. N. Dengen, N. Dengen, and I. Islamiyah, "Sistem Pendukung Keputusan Pemilihan Pegawai Teladan FKTI Menggunakan Metode AHP," J. Rekayasa Teknol. Inf., vol. 2, no. 2, p. 182, 2018, doi: 10.30872/jurti.v2i2.1873.

[6] K. Safitri and F. Tinus Waruwu, "Sistem Pendukung Keputusan Pemilihan Karyawan Berprestasi Dengan Menggunakan Metode Analytical Hieararchy Process (Studi Kasus : PT.Capella Dinamik Nusantara Takengon),” vol. 1, no. 1, pp. 12-16, 2017.

[7] J. Simatupang, "Sistem pendukung keputusan penentuan karyawan terbaik menggunakan metode saw studi kasus amik mahaputra riau," Intra-Tech, vol. 2, no. 1, pp. 74-82, 2018, [Online]. Available: https://www.journal.amikmahaputra.ac.id/index.php/JIT/article/view/27.

[8] M. Badaruddin, "Sistem Pendukung Keputusan Penilaian Kinerja Karyawan Menerapkan Kombinasi Metode Simple Additive Weighting (SAW) dengan Rank Order Centroid (ROC),” J. Media Inform. Budidarma, vol. 3, no. 4, p. 366, 2019, doi: $10.30865 / \mathrm{mib} . v 3 i 4.1508$.

[9] S. N. Amida and T. Kristiana, "Sistem Pendukung Keputusan Penilaian Kinerja Pegawai Dengan Menggunakan Metode Topsis," JSAI (Journal Sci. Appl. Informatics), vol. 2, no. 3, pp. 193-201, 2019, doi: 10.36085/jsai.v2i3.415.

[10] A. Putra, D. H. Zulfikar, and A. I. Alfresi, "Sistem Pendukung Keputusan Penilaian Kinerja Pegawai Pada Pdam Martapura Oku Timur Menggunakan Metode Moora,” J. Digit. Teknol. Inf., vol. 3, no. 1, p. 1, 2020, doi: 10.32502/digital.v3i1.2419.

[11] O. Veza and N. Y. Arifin, "Sistem Pendukung Keputusan Calon Mahasiswa Non Aktif Dengan Metode Simple Additive Weighting," J. Ind. Kreat., vol. 3, no. 02, pp. 71-78, 2020, doi: 10.36352/jik.v3i02.29. 